\title{
Analysis of unstable mode of a free gas turbine of turbo-compressors engines
}

\author{
Marián Hocko ${ }^{1 *}$, and Samer Al-Rabeei ${ }^{2}$ \\ ${ }^{1}$ Technical University of Kosice, Faculty of Aeronautics, Department of Aerospace Engineering, \\ Rampová 704121 Kosice, Slovakia.
}

\begin{abstract}
This paper analyses unstable mode of a free gas turbine of turboshaft helicopter engine TV3-117. The analysis is focused on the conditions of this phenomenon and the possibilities of its solution in a turboshaft helicopter engine and an industrial turbocharger engine with a free gas turbine. Knowing the causes of the unstable mode of operation of a free gas turbine will allow helicopter pilots to prevent accidents and increase the level of flight safety.
\end{abstract}

\section{Introduction}

On May 10, 2017, a Bell 429 helicopter crash occurred at the airport in Prešov Fig. 1, killing two firefighters. The helicopter fell from a height of 100 meters during the training of planting firefighters using ropes. The inquiry commission proceeded that the noncompliance of the helicopter was an incorrect reaction of the pilot to the behaviour of the helicopter in the future when the free gas turbine of the engine entered the mode of unstable work [1].

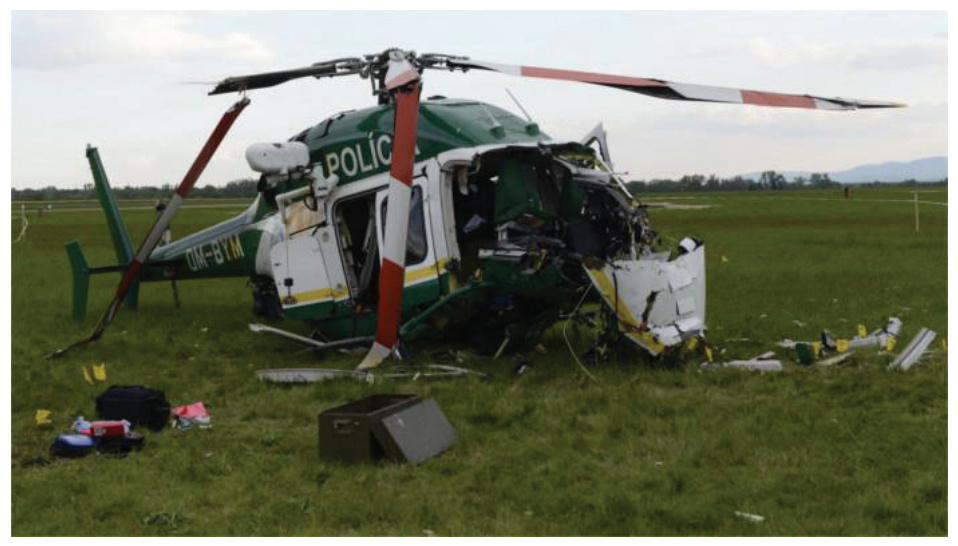

Fig.1. Helicopter Bell 429 crash near Prešov

* Corresponding author: marian.hocko@tuke.sk 
The issue of unstable operation of a free gas turbine of turboshaft helicopter engines is not given sufficient attention in the professional literature or in the training of pilots, despite the fact that it directly affects the safety of flights. For this reason, this article analyses the physical nature of this mode of a turboshaft engine with a free gas turbine.

Since the Bell 429 helicopter engine for Pratt \& Whitney Canada PW207D helicopter engines did not release all the technical data, the TV3-117 Mi-24 helicopter engine was used for analysis, which in terms of concept and principle of operation corresponds to the Pratt \& Whitney Canada PW207D Bell 429 helicopter engine. the turbine of the TV3-117 turboshaft engine could be realized thanks to the detailed knowledge of the construction and control system of the TV3-117 helicopter as well as the availability of its detailed technical documentation $[2,3]$.

\section{Regulatory system turboshaft engine helicopters}

The main task of the helicopter power unit, which currently usually consists of two turboshaft engines (Mi-2, Mi-17, Mi-24, Aerospatiale SA 330 Puma, NH-90, etc.), is to ensure the drive of the helicopter's supporting rotor during its flight. In any mode and maneuvers, as well as when starting the engines, turning and stopping the helicopter's supporting rotor. In steady-state modes of operation of the turboshaft engine functions, the automatic drive unit maintains the set speed of the supporting rotor. When switching to reduced engine power (reducing the setting angle of the carrier rotor blades, or when adjusting the correction handle to the left), insufficient torque (insufficient power) is generated on the free turbine of the turboshaft engine and the carrier rotor speed is reduced. When moving the collective control lever of the helicopter while the turboshaft engines are operating in steady state modes (travel, nominal or take-off), the pilot controls the change of the setting angle of the supporting rotor blades by means of the collective control lever. The control unit adjusts the fuel supply $\left(\mathrm{Q}_{\text {fuel }}\right)$ to the engine's main combustion chamber and maintains the selected speed.

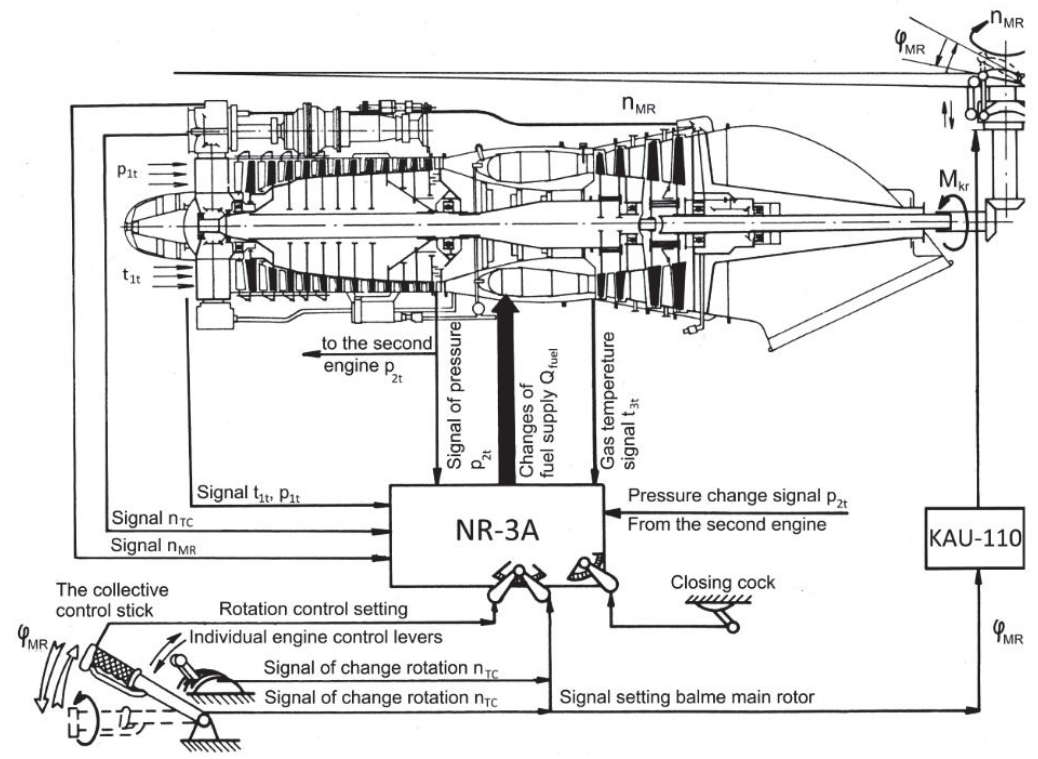

Fig. 1. Principle diagram of the collective control system with automatic maintenance of the rotor speed and control of the collective control of the helicopter rotor $[4,6]$. 
The TV3-117 aircraft turbo-compressor engine is a turboshaft engine with an axial inlet, a twelve-stage axial compressor with rotary vane blades and two air bleed valves, an annular combustion chamber, a two-stage axial, cooled gas turbine compressor an outlet system with the outlet tube rotated at an angle of $60^{\circ}$ to the right or left with respect to the engine [4].

Two TV3-117 3rd series turboshaft engines used to drive the Mi-24D and Mi-24DU helicopters, two TV3-117V engines of the Mi-24V drives the helicopter and two TV3$117 \mathrm{MT}$ engines drive the medium transport Mi-17 helicopter [5].

\section{Force analysis when changing the angle of attack of the main rotor of the helicopter}

When starting the engines and increasing the speed of the free turbine (when turning the correction handle to the right from idle to travel mode and when setting the collective control lever up), there is an excess torque (excess power) on the free turbine of the turboshaft engine, which is maintained until specified engine mode. With steady-state modes of operation of turboshaft engines, the automation of the drive unit ensures the maintenance of the set speed of the supporting rotor. However, the speed of the turbocharger rotor of the turboshaft engine changes in this case due to the load of the free gas turbine with the required torque (required power) as well as due to the change of the air temperature at the inlet to the engines $t_{1 t}$ (Fig. 2). When switching to reduced engine power (when reducing the setting angle of the carrier rotor blades and when setting the correction handle to the left to idle mode), the free gas turbine of the turboshaft engine generates insufficient torque (insufficient power) and the support rotor speed decreases. When moving the helicopter collective control lever while the turboshaft engines are operating in steady-state modes (travel, nominal, and take-off), the pilot controls the setting of the angle of adjustment of the supporting rotor blades by means of the collective control lever (by its continuous adjustment and complete rotation to the left) (Fig. 3). The fuel control system of the turboshaft engines adjusts the fuel supply to the main combustion chamber of the $Q_{\text {fuel }}$ engines accordingly and the selected speed of the helicopter support rotor is maintained. When the pilot stops moving the collective control lever upwards (ready to do so), the controller will maintain a constant helicopter carrier rotor speed at three higher turbocharger rotor speeds, and thus at a torque compensation greater than before the collective control lever position change (e.g. in cruising mode of turboshaft engines). In the take-off mode, depending on the angle pattern, the settings of the helicopter carrier rotor blades, and thus depending on the required torque, are the equilibrium speeds of the helicopter carrier rotor slightly lower than in the cruising or nominal mode. Part of the increased required torque is compensated by the increase in the angle of flow of the gas through the pipeline to the blades of the free gas turbines of the turboshaft engines due to certain reductions in their speed compared to the speed in travel or nominal mode. The angle of attack to the flow of gas leading edge of the rotor blades of the gas turbine of free critical value, so that the gas flow separation from the surface of the rotor blade does not occur $[7,11,12,13]$. 


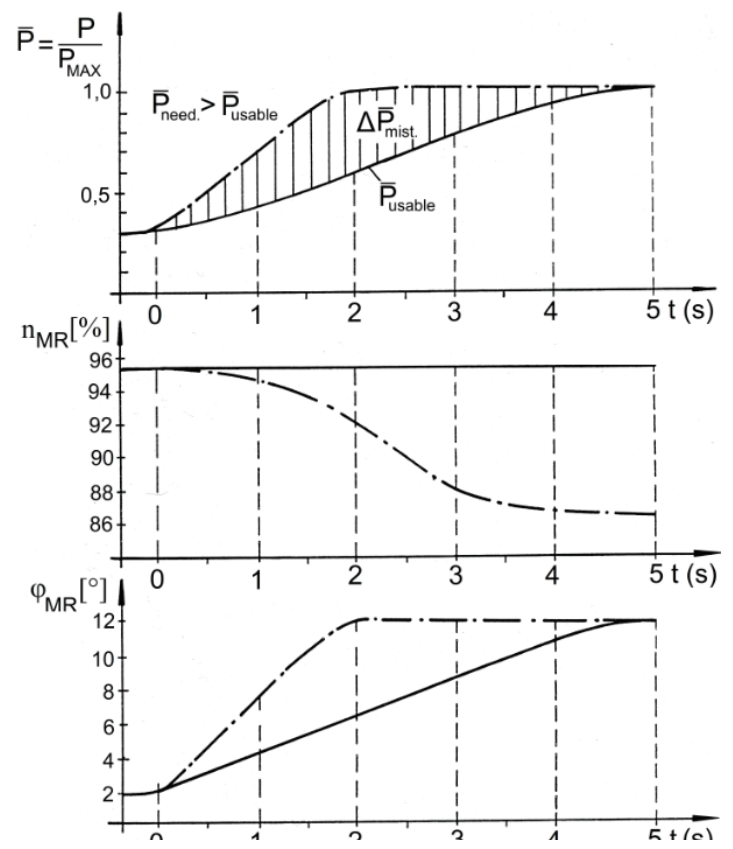

Fig. 2. Changes in relative power required $\bar{P}_{\text {Req. }}$, usable power $\bar{P}_{\text {Usable. }}$ and speed of the main rotor $\mathrm{n}_{\mathrm{MR}}$ as a function of time at different speeds of increasing the setting angle of the main rotor blades $\varphi_{\mathrm{MR}}$ (full line corresponds to the set speed of the collective control sausage in accordance with the regulations for use and piloting technique, collective control lever of the helicopter support rotor).

A sharp change in the position of the collective control lever by the pilot is not recommended. Rapid movements of the collective control lever of the helicopter support rotor can tear off the gas stream from the surface of the blades of the free gas turbine of the turboshaft engine and consequently reduce its effective power and decrease the speed of the helicopter support rotor.

\section{Unstable flow on a free gas turbine of a turboshaft helicopter engine}

Figure 4 shows an unstable bypass of the rotor blades of one of the stages of a free gas turbine of a helicopter engine with a turbo shaft. The tearing of the gas flow on the back of the rotor blade of the free gas turbine of the turboshaft engine can occur when the angle of attack of the flowing gas at the leading edge of the rotor blade increases above the critical value (Fig. 5), which occurs:

- with a sharp increase in the absolute output velocity of the flow, the pipeline exiting the blades of the free gas turbine $\left(c_{1}>c_{\text {cal }}\right.$.), and at a constant speed of the free gas turbine of the turboshaft engine and a constant, calculated circumferential speed $\left(\mathrm{u}_{1}=\mathrm{u}_{\text {cal }}\right.$.);

- with a sharp reduce in the speed of the free gas turbine of the turboshaft engine, at which the peripheral speed decreases $\left(\mathrm{u}_{2}<\mathrm{u}_{\mathrm{cal}}\right.$.), and a constant absolute output velocity of the gas flow from the guide blades of the free gas turbine $\left(c_{2}=c_{c a l}\right)$; 
- with increasing the absolute output velocity of the gas flow from the turbocharged engine free gas turbine blades $\left(c_{3}=c_{1}\right)$ and decreasing the turbocharged engine free gas turbine speed $\mathrm{u}_{3}=\mathrm{u}_{2}<\mathrm{u}_{\text {cal. }}$.).

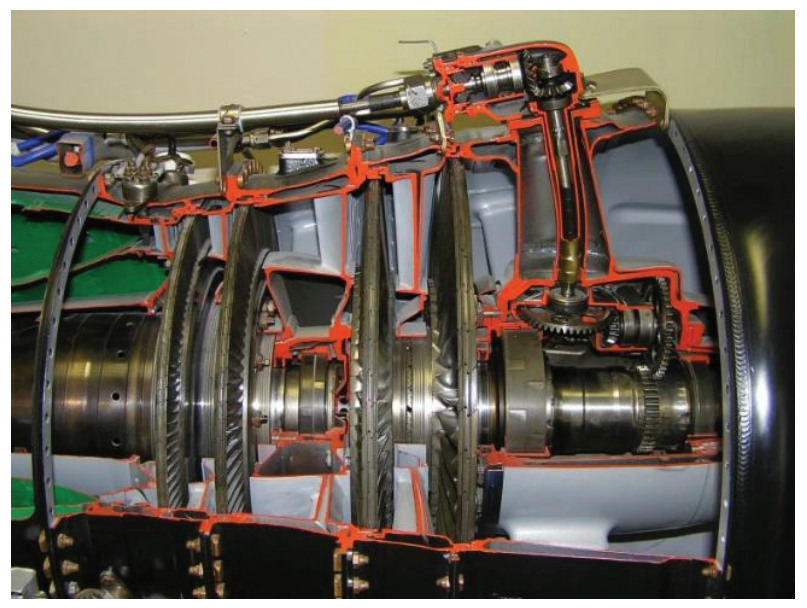

Fig. 4. Free turbine of the turboshaft engine TV3-117 [8]

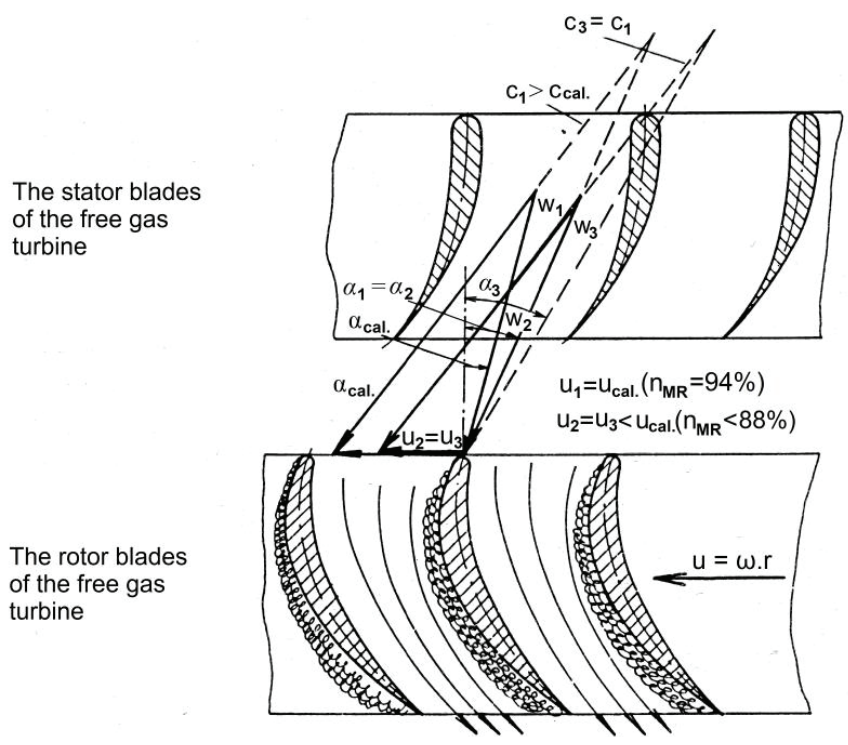

Fig. 3. Tearing of the gas flow at the back rotor blade of a free gas turbine, a turboshaft engine can occur when the angel's attack of the flowing gas at the leading edge for the rotor blade increases above a critical value $[4,6]$.

$\mathrm{c}_{\mathrm{cal}}$. - absolute design gas velocity at the outlet of the turbocharged engine free gas turbine blades $\left[\mathrm{m} . \mathrm{s}^{-1}\right]$;

w - relative velocity of the gas flow at the inlet to the rotor blades of the free gas turbine of the turboshaft engine $\left[\mathrm{m} . \mathrm{s}^{-1}\right]$;

$\mathrm{u}_{\mathrm{cal}}$. - calculating a rotor peripheral speed of the first step of free turbine turboshaft engine gas $\left[\mathrm{ms}^{-1}\right]$;

$\mathrm{u}_{1} \quad$ - peripheral speed of the first step of free turbine turboshaft engine gas for 
computing main rotor speed $\mathrm{n}_{\mathrm{MR}}=94 \%\left[\mathrm{~m} \cdot \mathrm{s}^{-1}\right]$;

$\omega$

- angular speed of the rotor blades of a free gas turbine of a turboshaft engine at the design speed of the supporting rotor [rad];

r

- radius of the rotor disk of the first stage of the free gas turbine of the turboshaft engine $[\mathrm{m}]$;

$\alpha$ - the angle of inclination of the gas flow at the leading edge of the rotor blades of the first stage of the free gas turbine of the turboshaft engine $\left[{ }^{\circ}\right]$;

$\alpha_{c a l}$. - the calculated angle of inclination of the gas stream at the leading edge of the rotor blades of the first stage of the free gas turbine of the turboshaft engine at the calculated speed of the supporting rotor $\left[^{\circ}\right]$;

$c_{1} \quad$ - the absolute flow velocity of the gas pipeline at the outlet of the deflector blades of the free gas turbine of the turboshaft engine, which corresponds to the speed of the main rotor $\mathrm{n}_{\mathrm{MR}}=94 \%\left[\mathrm{~m} . \mathrm{s}^{-1}\right]$;

$\alpha_{1} \quad$ - the angle of attack of the gas stream at the leading edge of the rotor blades of the first stage of the free gas turbine of the turboshaft engine, which corresponds to the speed of the main rotor $n_{M R}=94 \%\left[\mathrm{~m} \cdot \mathrm{s}^{-1}\right]$;

$\mathrm{w}_{1} \quad$ - the relative velocity of the gas flow at the inlet to the rotor blades of the free gas turbine of the turboshaft engine, which corresponds to the speed of the supporting rotor $\mathrm{n}_{\mathrm{MR}}=94 \%\left[\mathrm{~m} . \mathrm{s}^{-1}\right]$;

$\mathrm{u}_{2} \quad$ - peripheral speed of the first step of free turbine turboshaft engine of the gas in the main rotor speed $\mathrm{n}_{\mathrm{MR}}<88 \%\left[\mathrm{~m} \cdot \mathrm{s}^{-1}\right]$;

$\mathrm{c}_{2} \quad$ - the absolute flow velocity of the gas pipeline at the outlet of the deflection blades of the free gas turbine of the turboshaft engine, which corresponds to the speed of the main rotor $\mathrm{n}_{\mathrm{MR}}<88 \%\left[\mathrm{~m} . \mathrm{s}^{-1}\right]$;

$\alpha_{2} \quad$ - the angle of inclination of the gas flow at the leading edge of the rotor blades of the first stage of the free gas turbine of the turboshaft engine, which corresponds to the speed of the supporting rotor $\mathrm{n}_{\mathrm{MR}}=94 \%\left[^{\circ}\right]$.
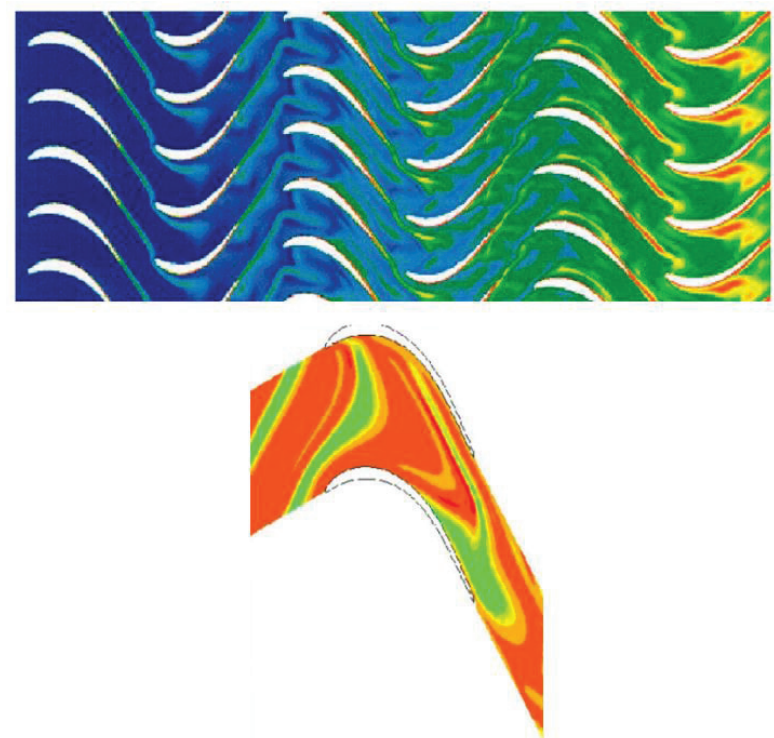

Fig. 4. Visualized character of gas flow in a multistage gas turbine and on the back of the stator blade of a free gas turbine of a turboshaft engine [9]. 
The Figure 6 shows a visualization of the tear-off of the jets at the gas turbine stages obtained under laboratory conditions $[9,10]$.

To tear off the gas flow can also be torn off in the rotor blade of the free gas turbine of the turboshaft engine (Fig. 7) with a considerable reduction of the flow angle of the flowing gas at the leading edge of the rotor blade below the critical value:

- with a sharp reduction in the absolute output velocity of the gas flow from the free gas turbine blades $\left(\mathrm{c}_{1}<\mathrm{c}_{\text {cal }}\right.$.) and a constant free gas turbine engine speed of constant, calculated peripheral speed $\left(\mathrm{u}_{1}=\mathrm{u}_{\mathrm{cal}}\right.$.);

- while reducing the absolute output velocity of the gas stream from the free gas turbine blades $\left(\mathrm{c}_{2}{ }^{\prime}=\mathrm{c}_{\mathrm{cal}}\right.$. $)$ and increasing the free gas turbine speed $\left(\mathrm{u}_{2}{ }^{\prime}<\mathrm{u}_{\mathrm{cal}}.\right)$.

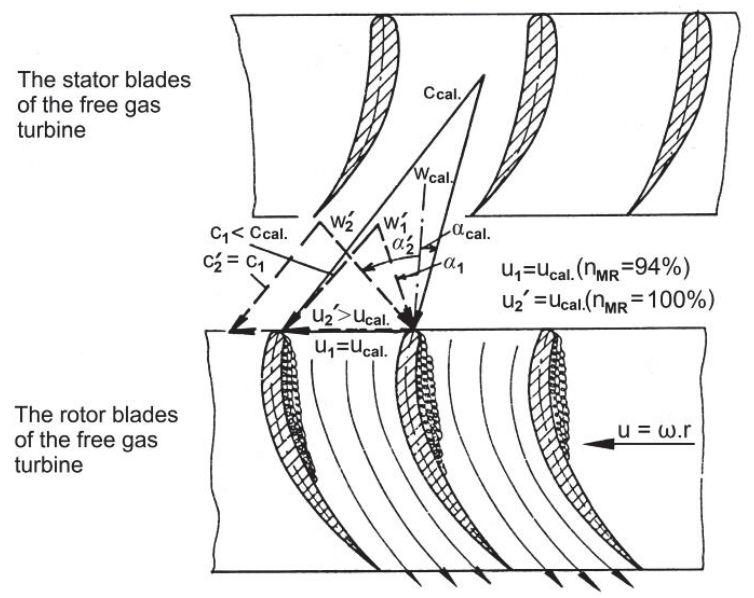

Fig. 5. Tearing of the gas flow at the blade rotor blade of a free gas turbine, a turboshaft engine can occur when the angel's attack of the flowing gas at the leading edge for the rotor blade increases above a critical value $[4,6]$.

Where:

$\mathrm{u}_{2}{ }^{\prime} \quad$ - peripheral speed of the first step of free turbine turboshaft engine of the gas in the main rotor speed $\mathrm{n}_{\mathrm{MR}}=100 \%\left[\mathrm{~m} . \mathrm{s}^{-1}\right]$;

$\mathrm{w}_{2}{ }^{\prime} \quad$ - the relative velocity of the gas flow at the inlet to the rotor blades of the free gas turbine of the turboshaft engine, which corresponds to the speed of the main rotor $\mathrm{n}_{\mathrm{MR}}=100 \%\left[\mathrm{~m} \cdot \mathrm{s}^{-1}\right]$;

$\alpha_{2}^{\prime} \quad$ - the angle of an attack of the gas stream at the leading edge of the rotor blades of the first stage of the free gas turbine of the turboshaft engine, which corresponds to the speed of the main rotor $\mathrm{n}_{\mathrm{MR}}=100 \%\left[\mathrm{~m} \cdot \mathrm{s}^{-1}\right]$.

In operation, the gas flow on the back of the rotor blades of a free gas turbine of a turboshaft engine is torn off most often when the carrier rotor speed drops below $\mathrm{n}_{\mathrm{MR}}=$ $88 \%$, regardless of the mode in which the turbo-compressors turboshaft (take-off, nominal, touring) operates.

In this case, the free gas turbine speed controller will increase the fuel supply to the engine's main combustion chamber to increase the free gas turbine power and adjust the support rotor speed to the desired value. Because at this point the angle of attack of the flowing gas at the leading edges of the rotor blades of the free gas turbine has reached a critical value, there is no increase in torque or power at the output shaft of the free gas turbine. In addition, assuming that the flow rate of gases from the blades of the free gas turbine of a turbocharged engine increases even more at this point, the flow angle of the 
flowing gas at the leading edge of the rotor blades will be even more supercritical so that the expected increase in torque due to increased speed flowing gas will not occur. This is due to the fact that by tearing off the gas stream, an increase in energy is absorbed, and increased gas flow rate is obtained, and the speed of the free gas turbine of the turboshaft engine decreases further. In operation, the gas turbine of the turboshaft engine may be selected to get into such a mode of a breakaway of the gas flow on the rotor blades free gas turbine if the collective control lever is set abruptly (determined as long as allowed) from the idle position to the position corresponding to take-off position. When the position of the carrier rotor blades changes abruptly to a large angle of attack, they increase just as fast to load the free gas turbine with increased torque, to a given mode. The speed of the helicopter's supporting rotor decreases rapidly and can fall below $\mathrm{n}_{\mathrm{MR}}=88 \%$. Although the turboshaft engine compressor will operate at maximum power during the rest of the engine operation, the angles of attack of the flowing gas at the leading edges of the rotor blades of the free gas turbine will be supercritical. If at this point, the pitch angle of the helicopter carrier rotor blades is further increased, then it will further complicate the existing situation. The helicopter's supporting rotor is overloaded and will not operate to develop the necessary thrust for the helicopter flight in the given helicopter flight mode. Frequent and long-term operation of a free gas turbine of a turboshaft engine in such or a similar mode contributes to a premature reduction in effective power and is not ruled out or damaged by the turboshaft engine. For this reason, the speed-changing position of the collective control lever must not exceed the specified value specified in the regulation for the use of the given type of helicopter.

\section{Conclusion}

As noted in the article, the nature of the flow on the rotor blades of a free gas turbine directly affects the efficiency of converting thermal energy into mechanical power free turbine turboshaft helicopter gas engine, which has a direct impact on the flight safety of the helicopter. For this reason, an understanding of these processes is of particular importance to helicopter pilots. Analogous processes also occur in industrial turboshaft engines with a free gas turbine, which drives electric generators in power plants or drives compressors in compressor stations of gas pipelines. These turbocharged engines experience the above processes due to a sharp change in the load of the electric generator or compressor.

\section{References}

1. Top. helicopter pad in press. Online: https://www.topky.sk/cl/100370/1688821/The reversal in the investigation of the fall of the vertical in the press everything is otherwise this should be the cause. 2018(sk).

2. Turning motor TV3-117, Manual of technical operation, PLN 078.00.5700, Book $1(\mathrm{RU})$.

3. Helicopter Mi-24V, Instructions for the helicopter crew, Part 1, Flight operation.9 (RU).

4. M. Hocko, Engine design TV3-117, VSŠL Košice, 2002, p. 169. (SK)

5. Using and piloting a helicopter Mi-17, Let-3-76. (SK)

6. Helicopter Mi-24V, Instructions for the helicopter crew, Part 1, Flight operation.(SK)

7. J. Růžek, Theory of aircraft engines I, VA AZ 1979, p. 373.(CZ)

8. M. Hocko, Turboshaft helicopter engines used in Czechoslovak, Czech and Slovak military aviation, LF TUKE Košice 2019, ISBN 978-80-553-3493-6, p. 220.(SK) 
9. R. J. Howell, Unsteady Turbine Aerodynamics - from the Laboratory to the Engine, Whittle Laboratory Cambridge University Department of Engineering.

10. M. Hocko, Introduction to engine design TV3-117, VSŠL Košice, 2001, p. 120.(SK)

11. A.R. Samer, M. Hovanec, P. Korba, Y. J. Patel, J., V. Lukač, I. Vasilčin, B. Wysoczańská, M. Golisová, Enhancing the Aircraft maintenance management process for increasing safety Saleh ... [ et al.] - 2022. In: 5th EAI International Conference on Management of Manufacturing Systems. - Cham (Switzerland) : Springer Nature s. 113 [online]. - ISBN 978-3-030-67240-9.

12. G. A. Misté, E. Benini Performance of a turboshaft engine for helicopter applications operating at variable shaft speed - 2012. In: Proceedings of the ASME 2012 Gas Turbine India Conference GTINDIA2012 - , Mumbai, Maharashtra, India.

13. W. Garre, T. Pflumm, M. Hajek, Enhamced efficiency and flight envelope by variable main rotor speed for different helicopter configurations - 2016. 42st European Rotorcraft Forum 2016. 